\title{
Antioxidant effect of 5-amino salicylic acid on copper- mediated LDL oxidation
}

\author{
CAMILO LÓPEZ-ALARCÓN ${ }^{1}$, HERNÁN SPEISKY ${ }^{2}$, EDUARDO LISSI ${ }^{3 *}$
}

${ }^{1}$ Departamento de Farmacia, Facultad de Química, Pontificia Universidad Católica de Chile, Santiago, Chile.
${ }^{2}$ Instituto de Nutrición y Tecnología de los Alimentos, Universidad de Chile, Santiago, Chile.
${ }^{3}$ Facultad de Química y Biología, Universidad de Santiago de Chile, Casilla 40- correo-33, Santiago, Chile.

\section{ABSTRACT}

The antioxidant effect of 5-Aminosalicylic acid (5-ASA) on copper-mediated LDL oxidation was followed either by the emitted chemiluminiscence (CL) or by UV-vis spectroscopy. 5-ASA addition extends the lag phase in a concentration-dependent manner without changes in the rate of the process in the autoaccelerated phase. The antioxidant behavior of 5-ASA was very similar to that of Trolox, a very efficient water soluble antioxidant.

The copper-binding capacity of 5-ASA was evaluated by UV-visible spectroscopy. The addition of copper to a 5-ASA solution increases the absorbance at $332 \mathrm{~nm}$ and generates a new band at $298 \mathrm{~nm}$. These changes in the UV-vis spectra indicate formation of a complex between 5-ASA and copper. However, LDL protection by 5-ASA is unrelated to its copper chelating capacity.

Key terms: 5-Aminosalicylic acid, Antioxidant, LDL oxidation.

\section{INTRODUCTION}

5-Aminosalicylic acid (5-ASA) is an antiinflammatory drug widely used in the therapy of bowel diseases, such as Crohn's disease and ulcerative colitis (Hanauer \& Present, 2003). 5-ASA has shown to be an efficient scavenger of oxygen free radicals, reactive species that play a significant role in the pathogenesis of inflammatory disorders of the gastrointestinal tract (Conner et al., 1996). The antioxidant effect of 5-ASA has been evaluated mainly in lipid peroxidation of membranes (Goncalves et al., 1998a; Dinis et al., 1994; Kanski et al., 2001; Pearson et al., 1996). Depending on the free radical source employed, 5- ASA has been proposed to be either less (Goncalves et al., 1998a) or more reactive (Pearson et al., 1996) than ascorbic acid towards peroxyl radicals. The oxidation of human low-density lipoprotein (LDL) is an early event in atherogenesis (Ross, 1993). The lipoprotein oxidation can, at least in vitro, be inhibited or delayed by antioxidants, such as phenols or polyphenols (Brown et al., 1998). However, the antioxidant effect of 5-ASA on the LDL oxidation has not been evaluated. Therefore, we present data bearing on the efficiency and mechanism of 5-ASA protection of LDL oxidation.

\section{MATERIALS AND METHODS}

\section{Chemicals}

5-ASA and Trolox (Fig. 1) were purchased from Sigma-Aldrich (St. Louis, MO). Copper sulfate was purchased from Merck. All chemicals were employed as received.

\section{LDL isolation}

Human LDL (1.019-1.063 g/mL) were prepared by zonal centrifugation from plasma obtained from normolipemidic blood 
donors. Prior to oxidation, EDTA in the LDL solution was removed with two passages through an Econo-Pac 10G desalting column (Bio-Rad, Richmond, CA) hydrated and eluted with phosphate buffered saline (PBS). Protein concentrations in LDL preparations were determined by a modification of the Lowry method using bovine serum albumin as a reference standard (Hotzer et al., 2005). After elimination of EDTA, LDL samples were kept at $4{ }^{\circ} \mathrm{C}$ and used less than five days after purification. Some samples ("old" LDL samples) were employed two months after EDTA removal.

\section{Inhibition of copper-mediated LDL oxidation by 5-ASA}

The extent of LDL oxidation induced by copper addition was followed by the increase in absorbance at $234 \mathrm{~nm}$, due to the formation of conjugated diene hydroperoxides, and by the emitted lowlevel chemiluminescence (CL). The reaction mixture containing LDL $(11.3 \mu \mathrm{g} /$ $\mathrm{mL})$ plus copper sulfate $(5 \mu \mathrm{M})$ with or without 5-ASA or Trolox $(0.1-1 \mu \mathrm{M})$, was incubated in PBS buffer ( $\mathrm{pH} 7.4$ ) at $37^{\circ} \mathrm{C}$ in the thermostatized cuvette of a Shimadzu $2401 \mathrm{UV}$-visible spectrophotometer. Lowlevel chemiluminescence was measured in samples incubated at room temperature (22 $\left.{ }^{\circ} \mathrm{C}\right)$ in a Beckman LS-6500 liquid scintillation counter operating in the "out of coincidence" mode.

\section{Chelating of Copper by 5-ASA}

Complex formation between 5-ASA and copper was studied by UV-visible spectroscopy. The experiments were carried out in water containing $50 \mu \mathrm{M}$ of 5- ASA and 10-600 $\mu \mathrm{M}$ copper sulfate. UV-vis spectra were registered in a Hewlett Packard 8453 (Palo Alto, CA, USA) spectrophotometer at room temperature.

\section{RESULTS AND DISCUSSION}

\section{Copper-mediated LDL oxidation}

Copper mediated LDL oxidation was followed either by UV-vis spectroscopy or by the emitted chemiluminiscence (CL) assay. For both techniques a typical sigmoidal profile of an autocatalytic process was observed (Fig. 2A). The differences observed in the lag-phase $\left(\mathrm{t}_{\text {lag }}\right)$ (longer in the CL measurements) are due to the lower temperature of these experiments. Furthermore, it must be considered that, while the absorbance is directly related to product formation (conjugated dienes), the $\mathrm{CL}$ is a rate whose intensity is determined by the concentration of the emitting species (Lissi et al., 1988).

There are several parameters, additional to the $\mathrm{t}$ lag, which can be obtained from diene concentration $v s$ time profiles. For example, it is possible to evaluate the time

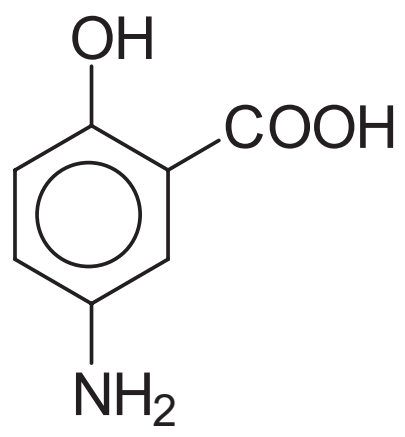

5-ASA

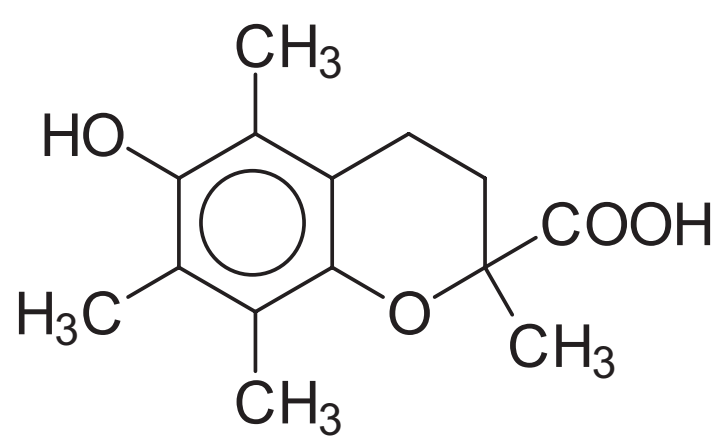

TROLOX

Figure 1: Chemical structure of 5-ASA and Trolox. 
required to reach half maximum diene concentration ( $\mathrm{t} 1 / 2$ ), and the maximum velocity $(v)$ of the lipid peroxidation, given by the peak of the first derivative (Fig. 2B) (Gieseg \& Esterbauer, 1994). Furthermore, the maximum diene concentration (diene max) can be estimated from the maximum increase of the absorbance at $234 \mathrm{~nm}$. The conversion of absorbance into diene concentration is based on a molar absorptivity $(\varepsilon)$ of $29.500 \mathrm{M}^{-1} \mathrm{~cm}^{-1}$ at 234 nm (Gieseg \& Esterbauer, 1994). In our experimental conditions, in a typical experiment in absence of additives, a $t_{\text {lag }}=$ $44 \min , \mathrm{t}_{1 / 2}=59 \mathrm{~min}, v=0.13 \mu \mathrm{M} / \mathrm{min}$, and $\left[\right.$ diene $\left.{ }_{\max }\right]=3.4 \mu \mathrm{M}$ was found. These values were somehow dependent on the LDL sample considered.
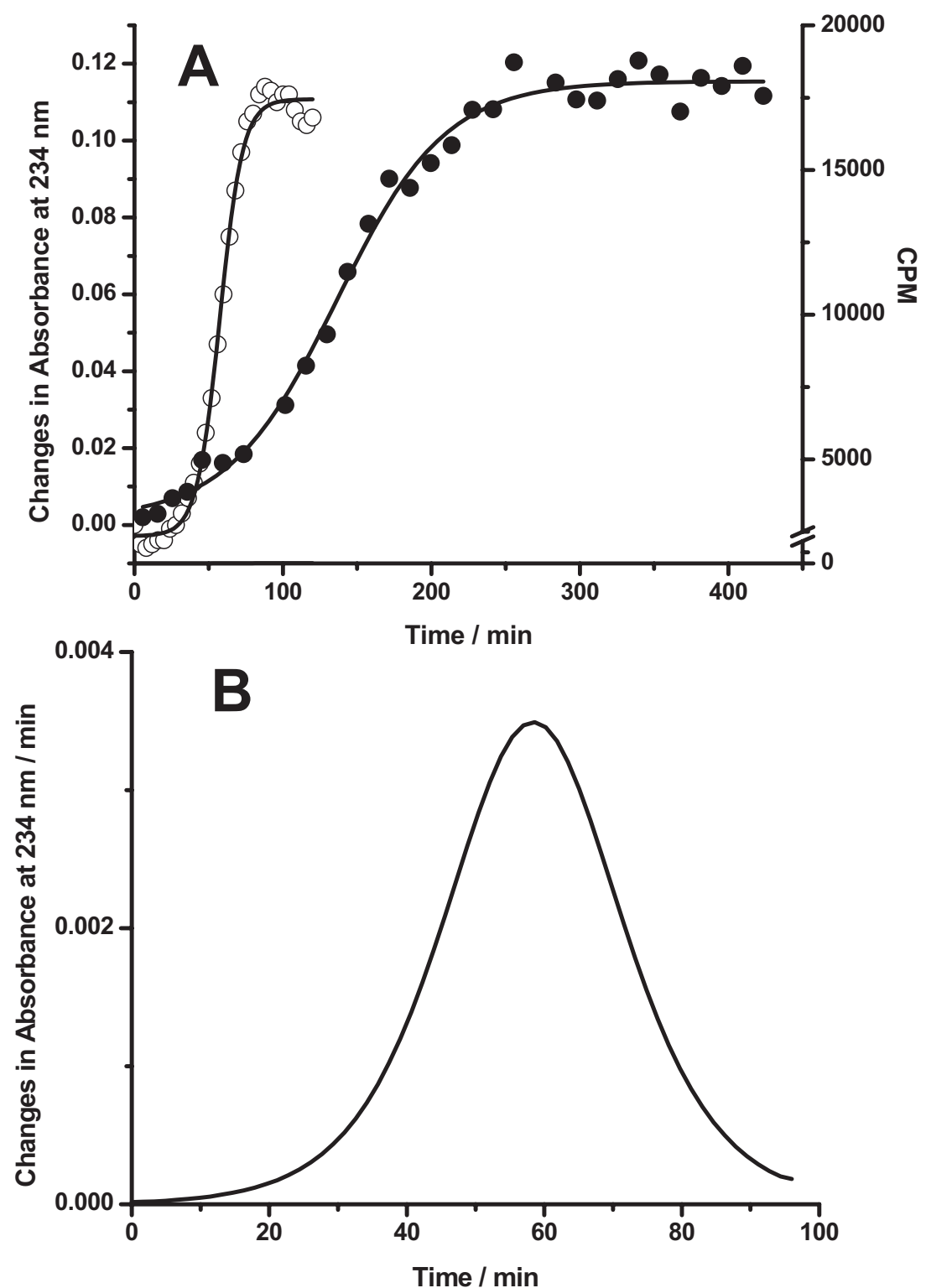

Figure 2: Continuous monitoring of copper-mediated LDL oxidation. LDL solution $(11.3 \mu \mathrm{g} / \mathrm{mL})$ in PBS at pH 7.4 supplemented with $5 \mu \mathrm{M} \mathrm{CuSO} 4$. A: $(\bigcirc)$ Change in absorbance measured at 234 $\mathrm{nm}$. Temperature $=37{ }^{\circ} \mathrm{C}$. (O) Chemiluminescence of the LDL suspension. Temperature $=22{ }^{\circ} \mathrm{C} . \mathrm{B}$ : First derivative of the absorbance vs time. The Absorbance $v s$ time data has been adjusted to a sigmoidal profile and the first derivative taken from the simulated points. 
Inhibition of copper-mediated LDL oxidation by 5-ASA

The effect of 5-ASA was examined on copper-mediated LDL oxidation. As shown in Fig. 3, either by CL or by UV-visible spectroscopy, 5-ASA extended the lag time of the oxidation process. The protection afforded by 5-ASA addition is only slightly smaller than that elicited by Trolox (Fig. 4), a very efficient water soluble antioxidant $(\mathrm{t}$ lag 5 -ASA $=197$ and $t_{\text {lag }}$ Trolox $=242 \mathrm{~min}$ at $0.5 \mu \mathrm{M}$ by $\mathrm{CL})$. Either for 5-ASA or Trolox the $\mathrm{t}_{\text {lag }}$ increased in a concentrationdependent manner (insert Fig. 4), delaying the start of the propagation phase even at the lowest assayed concentration $\left(\mathrm{t}_{\text {lag }}=98\right.$ min at 5-ASA 0.1 $\mu \mathrm{M}$ by CL). However, no changes in the rate of the process taking place after the lag phase are observed (Fig. 3B). The delay of LDL oxidation elicited by submicromolar 5-ASA concentrations could be of physiological significance since a simple dose of 5-ASA administered to patients with ulcerative proctitis leads to micromolar plasma concentrations of the drug (Aumais et al., 2003). Furthermore, the levels of 5-ASA concentrations have the same order of magnitude than plasma vitamin $\mathrm{E}$ and they are considerably higher than polyphenol concentrations, following the intake of antioxidant-rich beverages, such as tea or wine (Behrens et al., 1982; Widlansky et al., 2005).

The antioxidant effect of 5-ASA was evaluated in "old" LDL samples. These samples are devoid of endogenous antioxidants, as evidenced by the lack of an induction time (Fig. 5). No protection of LDL oxidation was observed when 5-ASA $0.5 \mu \mathrm{M}$ was added to the samples (Fig. 5). This lack of effect would indicate that the protection by 5-ASA requires the presence of the endogenous antioxidants $(\alpha-$ tocopherol). A plausible mechanism of action could be a recycling of the $\alpha$ tocopherol derived radicals by 5-ASA (Goncalves et al., 1998b). This proposal is compatible with the similarities of the reaction profiles shown in Fig. 3 .
Copper chelating capacity of 5-ASA.

Since the LDL oxidation employs copper as catalyst, we evaluated the capacity of 5ASA to chelate this ion. For this purpose, we determined the effect of copper (10$600 \mu \mathrm{M})$ upon the UV-visible spectrum of 5-ASA $(50 \mu \mathrm{M})$. The addition of copper produced both an increase of absorbance at $332 \mathrm{~nm}$ and a new band at $298 \mathrm{~nm}$ (Fig. 6). These changes indicate formation of a complex between 5-ASA and copper. Control solutions, containing either 5-ASA $(50 \mu \mathrm{M})$ or copper sulfate $(1 \mathrm{mM})$ were run in the same conditions without significant absorbances at the considered wavelengths. This proposal is compatible with the reported capacity of 5-ASA to chelate other $2+$ cations (Grisham et al., 1992). In the present system, a value of the association constant could not be obtained since there was not a linear correlation between the absorbance at $298 \mathrm{~nm}$ with $[\mathrm{Cu}(\mathrm{II})]_{\text {free }} \mathrm{x}[5-\mathrm{ASA}]_{\text {free }}$, suggesting that complex formation does not respond to a simple 1:1 stoichiometry. The formation of a 5-ASA-copper(II) complex must then be considered in the interpretation of the present data. However, we consider that complex formation can not per se explain the protection of LDL oxidation afforded by 5-ASA. In fact, in the protection experiments the 5-ASA concentration is considerably smaller than that of the catalyst. Then, even if the complex is quantitatively formed, the free $\mathrm{Cu}$ concentration would be only slightly decreased. On the other hand, complex formation could protect the LDL if it competes with $\mathrm{Cu}(\mathrm{II})$ adsorption on the LDL, a pre-requisite for the initiation of the chain oxidation process. However, this competition would lead to a decrease in the rate of the process after the lag time. This effect is not observed (Fig. 3) suggesting that 5-ASA protection is not due to a reduction in the rate of the initiation process. This is further supported by the lack of effect observed employing “old" LDL samples (Fig. 5). 

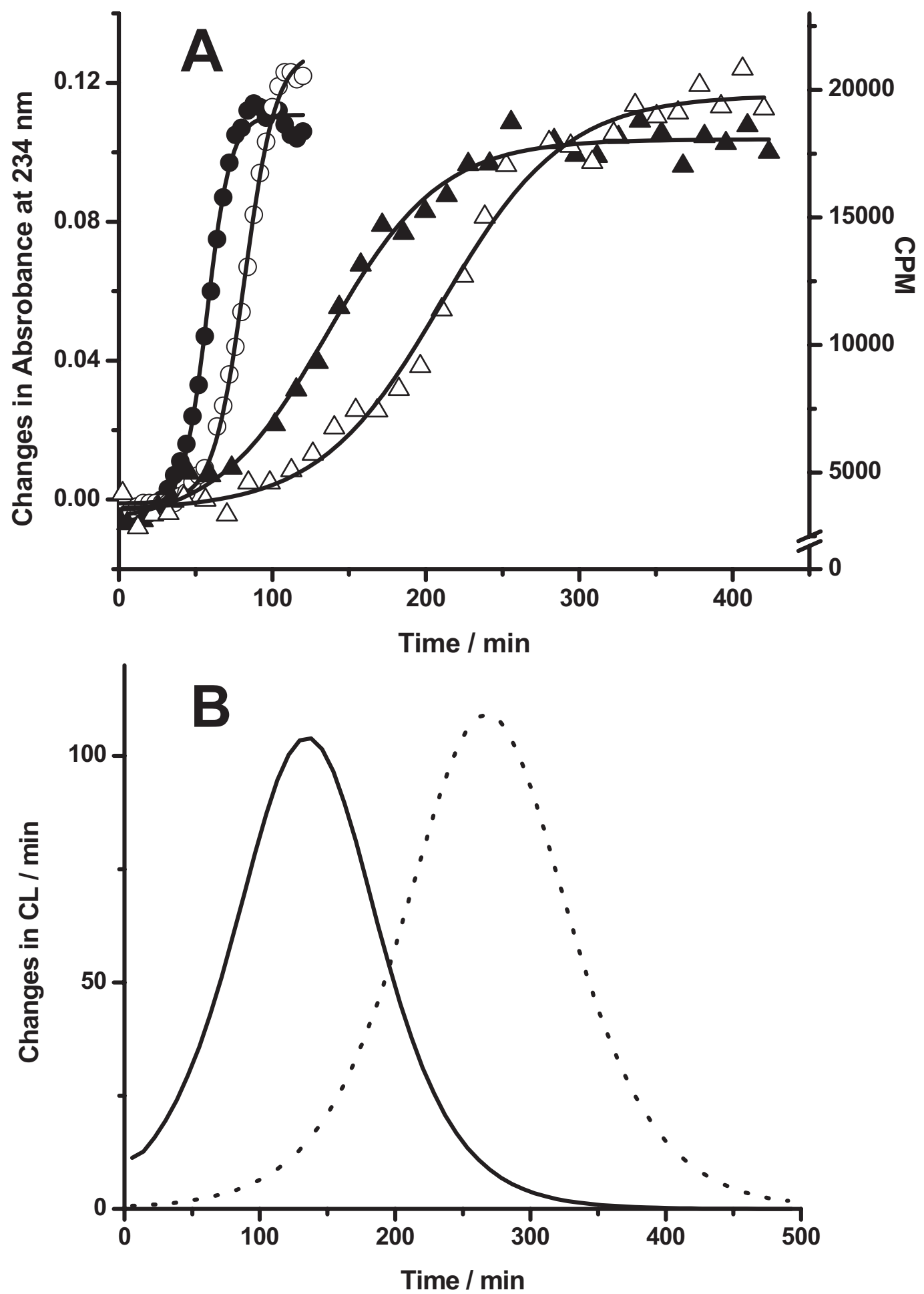

Figure 3: Effect of 5-ASA on copper-mediated LDL oxidation. LDL solution $(11.3 \mu \mathrm{g} / \mathrm{mL})$ in PBS at pH 7.4 supplemented with $5 \mu \mathrm{M} \mathrm{CuSO} 4$. A: (O) Absorbance at $234 \mathrm{~nm}$. Control without 5-ASA.; (O) Absorbance at $234 \mathrm{~nm}$ in presence of $0.2 \mu \mathrm{M}$ 5-ASA; ( $\mathbf{\Delta}) \mathrm{CL}$ of the LDL suspension. Control without 5-ASA; $(\Delta) \mathrm{CL}$ in presence of $0.2 \mu \mathrm{M}$ 5-ASA. B: First derivative of the CL vs time plots. Data obtained in absence (-) and in presence (- - ) of $0.5 \mu \mathrm{M}$ 5-ASA. The original data (CPM $v s$ time) has been adjust to a sigmoidal profile, and the first derivative taken from the simulated points. 


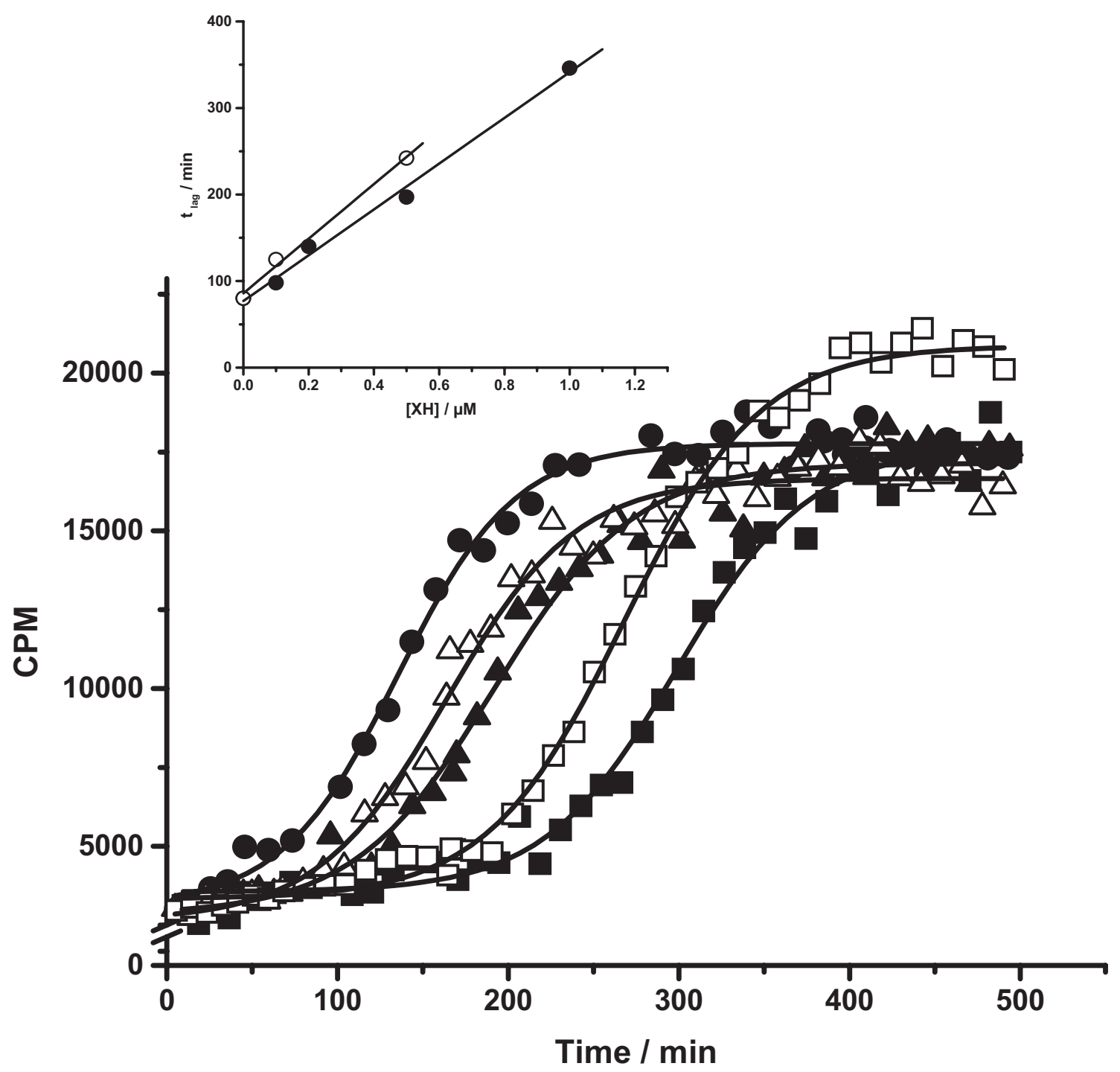

Figure 4: Effect of either 5-ASA or Trolox on the CL associated to copper- mediated LDL oxidation. LDL solution $(11.3 \mu \mathrm{g} / \mathrm{mL})$ in PBS at $\mathrm{pH} 7.4$ with or without antioxidants was supplemented with $5 \mu \mathrm{M}$ CuSO4. Control (O); 5-ASA $0.1 \mu \mathrm{M}(\Delta)$; 5-ASA $0.5 \mu \mathrm{M}(\square)$; Trolox 0.1 $\mu \mathrm{M}(\mathbf{\Delta})$; Trolox $0.5 \mu \mathrm{M}(\boldsymbol{\square})$. Insert: Dependence of $\mathrm{t}_{\mathrm{lag}}$ on the 5-ASA (O) or Trolox $(\bigcirc)$ concentration.

\section{CONCLUSIONS}

5-ASA micromolar concentrations retard copper-mediated LDL oxidation. 5- ASA efficiency is only slightly smaller than that of Trolox. From changes in the UV- vis spectrum of 5-ASA induced by copper sulfate it can be concluded that 5-ASA is able to complex $\mathrm{Cu}$ (II) ions. However, this process would be unrelated to the 5- ASA inhibitory effect. The protection afforded could be due to a chain breaking effect of 5-ASA or, more probably, to a reduced rate of consumption of the LDL endogenous antioxidants.

\section{ACKNOWLEDGMENTS}

This work was supported by FONDECYT (Projects 3040002 and 1030033). 


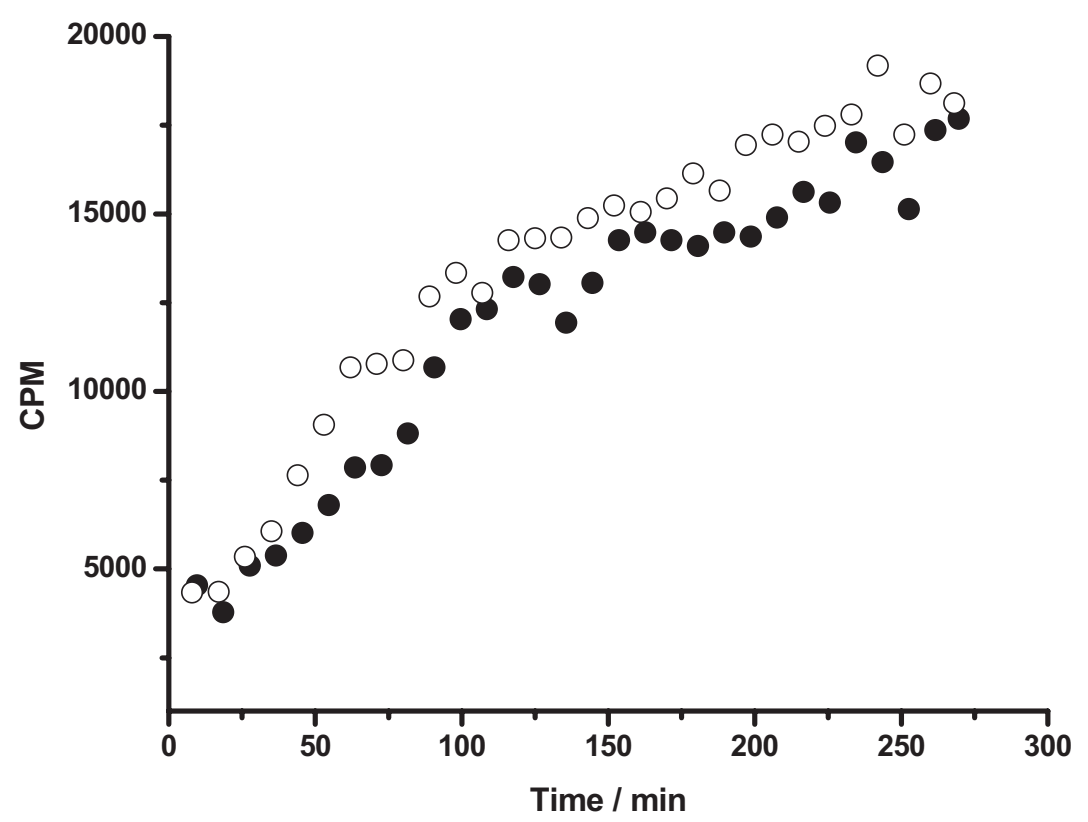

Figure 5: Effect of 5-ASA on the CL associated to the copper-mediated oxidation of an "old" LDL sample. LDL solution $(11.3 \mu \mathrm{g} / \mathrm{mL}$ ) (see experimental section) in PBS at pH 7.4 with or without 5ASA was supplemented with $5 \mu \mathrm{M}$ CuSO4. Control, (O). 5-ASA $0.5 \mu \mathrm{M}$ (O).

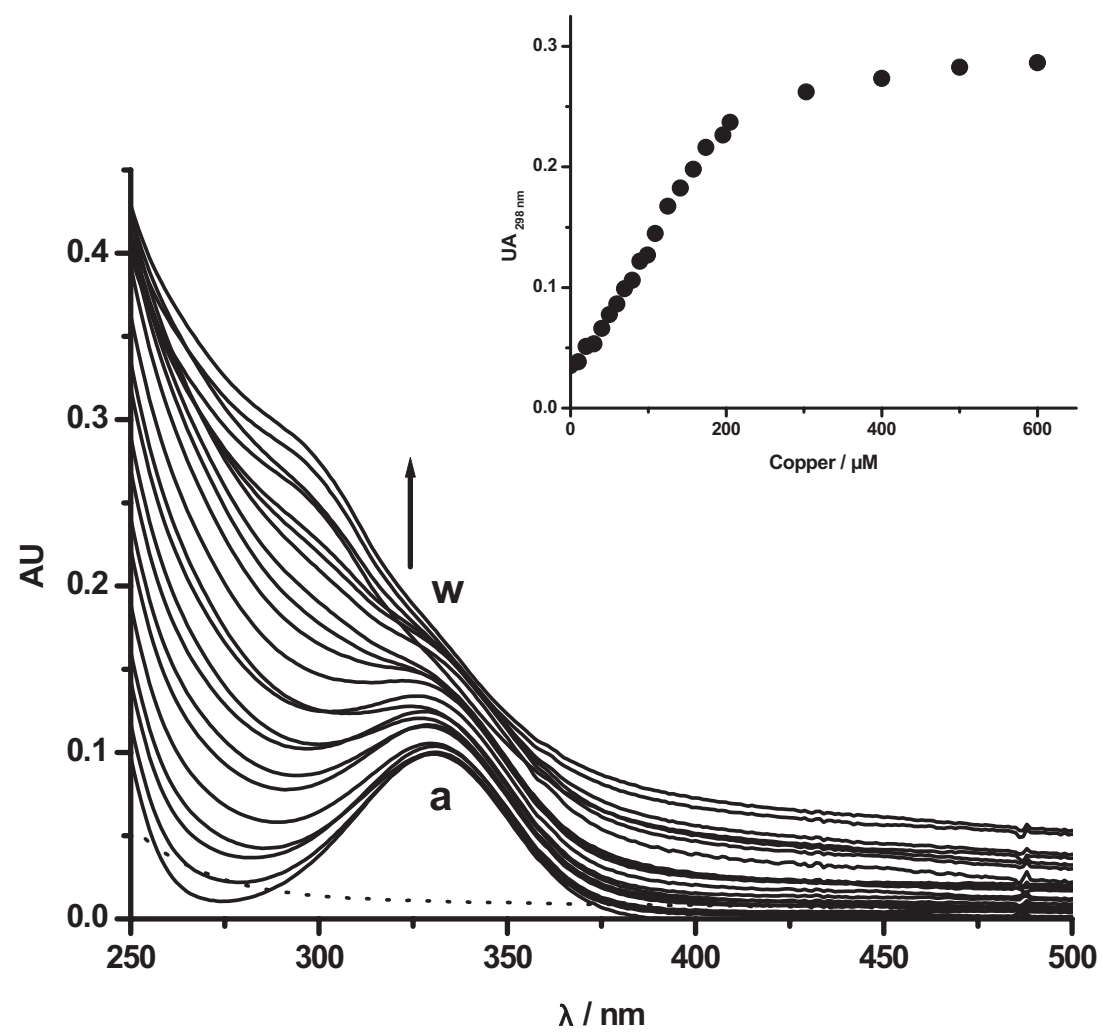

Figure 6: Effect of copper sulfate $(10-600 \mu \mathrm{M})$ on the UV-vis spectra of 5-ASA $(50 \mu \mathrm{M})$ in water. Doted line $=$ copper sulfate $1 \mathrm{mM}$ without 5-ASA. Lines a to line w, 5-ASA $50 \mu \mathrm{M}$ with increasing concentrations of $\mathrm{Cu}$ (II) from zero to $600 \mu \mathrm{M}$. Insert: Dependence of the absorbance at $298 \mathrm{~nm}$ on copper concentration. 


\section{REFERENCES}

AUMAIS G, LEFEBVRE M, TREMBLAY C, BITTON A, MARTIN F, GIARD A, MADI M, SPENARD J (2003) Rectal tissue, plasma and urine concentrations of mesalazine after single and multiple administrations of $500 \mathrm{mg}$ suppositories to healthy volunteers and ulcerative proctitis patients. Aliment Pharmacol Ther 17: 93-97

BEHRENS W, THOMPSON J, MADERE R (1982) Distribution of alpha-tocopherol in human plasma lipoproteins. Am J Clin Nutr 35: 691-696

BROWN J, KHODR H, HIDER R, RICE-EVANS C (1998) Structural dependence of flavonoid interactions with $\mathrm{Cu} 2+$ ions: implications for their antioxidant properties. Biochem J 330: 1173-1178

CONNER E, BRAND S, DAVIS J, KANG D, GRISHAM M (1996) Role of reactive metabolites of oxygen and nitrogen in inflammatory bowel disease: toxins, mediators, and modulators of gene expression. Inflamm Bowel Dis 2: 133-147

DINIS T, MADEIRA V, ALMEIDA L (1994) Action of phenolic derivatives (acetaminophen, salycilate and 5aminosalycilate) as inhibitors of membrane lipid peroxidation as peroxyl radicals scavengers. Arch Biochem Biophys 315: 161-169

GIESEG S, ESTERBAUER H (1994) Low density lipoprotein is saturable by pro-oxidant copper. FEBS Lett 343: 188-194.

GONÇALVES E, ALMEIDA L, DINIS T (1998a) Antioxidant activity of 5-ASA against lipid peroxidation in the presence of vitamin $\mathrm{C}$ and $\mathrm{E}$. Int $\mathrm{J}$ Pharm 172: 219-228

GONÇALVES E, ALMEIDA L, DINIS T (1998b) Antioxidant activity of 5-aminosalicylic acid against peroxidation of phosphatidylcholine liposomes in the presence of alpha-tocopherol: a synergistic interaction? Free Radic Res 29: 53-66

GRISHAM M, WARE K, MARSHALL S, YAMADA T, SANDHU I (1992) Prooxidant properties of 5aminosalicylic acid. Possible mechanism for its adverse side effects. Dig Dis Sci 37: 1383-1389

HANAUER S, PRESENT D (2003) The state of the art in the management of inflammatory bowel disease. Rev Gastroenterol Disord 3: 81-92

HOTZER K, HENRÍQUEZ C, PINO E, MIRANDAROTTMANN S, ASPILLAGA A, LEIGHTON F, LISSI E (2005) Antioxidant and pro-oxidant effects of red wine and its fractions on $\mathrm{Cu}(\mathrm{II})$ induced $\mathrm{LDL}$ oxidation evaluated by absorbance and chemiluminescence measurements. Free Radic Res 39: 175-183

KANSKI J, LAUDERBACK C, BUTTERFIELD D (2001) 5-aminosalycilic acid protection against oxidative damage to synaptosomal membranes by alkoxyl radicals in vitro. Neurochem Res 26: 23-29

LISSI E, CÁCERES T, VIDELA L (1988) Visible chemiluminescence from rat brain homogenates undergoing autoxidation. II. Kinetics of the luminescence decay. Free Radic Biol Med 4: 93-97

PEARSON D, JOURD'HEUIL D, MEDDINGS J (1996) The antioxidant properties of 5- aminosalicylic acid. Free Radic Biol Med 21: 367-373

ROSS R (1993) The pathogenesis of atherosclerosis a perpective for the 1990s. Nature 362: 801-809

WIDLANSKY M, DUFFY S, HAMBURG N, GOKCE N, WARDEN B, WISEMAN S, KEANEY J, FREI B, VITA J (2005) Effects of black tea consumption on plasma catechins and markers of oxidative stress and inflammation in patients with coronary artery disease Free Radic Biol Med 38: 499-506 